\section{ETUI Policy}

Brief

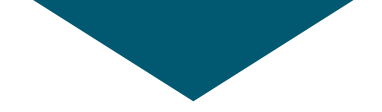

European Economic, Employment and Social Policy

2021.08

\section{Time to deliver? Assessing}

the Action Plan on the

European Pillar of Social

Rights

\section{Silvia Rainone and Antonio Aloisi}

\section{Policy implications}

researcher at the

European Trade

Union Institute (ETUI),

Brussels and affiliated

with KU Leuven.

Antonio Aloisi is Marie

Skłodowska-Curie

Fellow and Assistant

Professor at IE Law

School, Madrid.
- The Action Plan on the European Pillar of Social Rights (EPSR) and the Porto Social Summit have created a momentum for the enhancement of the social dimension of the European Union (EU), but, so far, without much to show by way of innovation.

- The EU should further expand the legislative agenda in the social and labour fields in order to address the risks of precariousness and degradation of working conditions faced by numerous workers in several sectors.

- The role of the EPSR and of the Social Scoreboard within the European Semester should also be significantly reinforced, so as to establish binding social safeguards supporting the betterment of working and living conditions.

- A highly crucial challenge for EU policymakers is to ensure that the recovery strategy and the digital and green transitions, beside contributing to job creation, also result in better social standards and good-quality professional opportunities. 


\section{The Porto Social Summit relaunches the EPSR Action Plan}

In March 2021, the European Commission (hereafter the Commission) adopted an Action Plan to implement the EPSR. The document outlined a series of initiatives geared towards attaining three targets:

- At least $78 \%$ of the population aged 20 to 64 should be in employment by 2030, which implies at least halving the gender employment gap;

- At least $60 \%$ of all adults should participate in training every year, and access to basic digital skills must be promoted for at least $80 \%$ of people aged 16-74;

- The number of people at risk of poverty or social exclusion should be reduced by at least 15 million by 2030, including 5 million children.

The EPSR and its roll-out through the Action Plan were publicly endorsed at the Social Summit in Porto on 7 and 8 May 2021, organised by the Portuguese Presidency of the European Council, whose motto has emphatically been 'it is time to deliver'. The Summit had thus long been awaited by those who crave a stronger reaffirmation of the social dimension of European integration (Fernandes and Kerneïs 2021).

On 7 May, the Commission, the European Parliament, representatives of civil society, and social partners signed the 'Porto Social Commitment', whereby they undertook to place the EPSR at the centre of the strategy for a sustainable and inclusive recovery. The next day, 8 May, the heads of state and government, in an informal gathering of the European Council, released the 'Porto declaration', which further stressed that the EPSR is a fundamental element of the recovery, as well as the importance of the Action Plan for achieving upward social and economic convergence in the post-pandemic phase.

The unity of the EU's main institutional players around the EPSR and the quantitative targets set in the Action Plan are laudable. By making the EPSR and the dedicated Action Plan an integral part of the EU recovery strategy, the Porto Social Summit has placed these initiatives at the forefront of the EU political mission, but now the time has really come for the institutions to demonstrate that their commitment to social values is more than rhetoric, and will be backed up by structural and effective measures (European Commission 2020).

This policy brief considers whether the Porto Social Summit and the Action Plan provide sufficient reassurance that this momentum will not be wasted and that the EU will improve its performance in the social and labour field. The main finding is that, so far, these recent initiatives do not provide any indication that the role of the EPSR will be substantially enhanced. The full achievement of the social targets in the current Action Plan will prove to be challenging, mostly due to the weak legal nature of the instruments proposed in the Action Plan and the moderate relevance of the EPSR in the EU governance and policymaking spheres. It is thus necessary to bolster the impact of the EPSR through a more ambitious legislative agenda and to consolidate its role in the context of the European Semester. 


\section{Looking backwards to see forward: ambitious targets and underwhelming results}

The EPSR Action Plan and the endorsement received at the Porto Social Summit are not unprecedented. It is not the first time that the EU has shown a strong sense of commitment to strengthening social and labour rights. The first Social Action Plan was launched in 1973, and already back then the primary aim was to reach full employment. Emphasis was placed on vocational training, retraining and professional rehabilitation. The following Social Action Plans, adopted in 1989, 1995 and 1998, essentially all reaffirmed commitments to job-creation efforts and the importance of enhancing skills through education and training.

More precise quantitative targets were adopted following the introduction of the Employment Title in the Treaty of Amsterdam, which called for the coordination of national employment policies. In 2000, the Lisbon Strategy aimed at raising the employment rate in the 15-64 age group from an average of $61 \%$ to $70 \%$ by 2010 , and at improving workers' training and digital skills. At the same time, it was established that the poverty level should drop significantly. In 2010, the Europe 2020 Strategy proposed even more ambitious objectives: to increase the employment rate, this time in the 20-64 age group, from $69 \%$ to $75 \%$ by 2020 , and to reduce the number of people at risk of poverty and social exclusion by 20 million. An 'Agenda for new skills and job' was also introduced.

These targets have not been met. According to Eurostat, in 2020 the employment rate in the 20-64 age group was $73 \%$ in the EU. There were 71 million people at risk of poverty and social exclusion in 2005, becoming 73 million in 2010 and reaching a peak in 2014 with 78 million before finally decreasing to 69 million in 2019. ${ }^{2}$ Adult participation in learning per year in the 25-64 age group has increased very slowly over the past 20 years, from around $5 \%$ in 2002 , to $7.5 \%$ in $2008,9.3 \%$ in 2014 and then $9.8 \%$ in $2019 .{ }^{3}$ Looking at adult participation in learning in the 16-74 age group, which is the reference group adopted by the Action Plan implementing the EPSR, the data seems a bit more encouraging: the percentage rose to 34.4\% in 2011 and 37.4\% in 2016 (European Commission 2021c).

Compared to these trends, the quantitative objectives of the EPSR Action Plan appear quite ambitious (Table 1) and place a considerable amount of pressure on the EU's performance to improve in the social and labour areas. To achieve its targets, however, the EU's rhetorical commitment needs to be reflected in concrete actions. To evaluate the reach of the instruments presented in the Action Plan, it is first helpful to analyse the shortcomings that have so far limited the transposition of the EPSR's principles.

1 https://ec.europa.eu/eurostat/databrowser/view/tesem010/default/line?lang=en

2 https://ec.europa.eu/eurostat/databrowser/view/t2020_50/default/line?lang=en. The data portrays EU population in consideration of the evolution of number of Member States within the Union (25 in 2004; 27 in 2007; 28 in 2013; 27 in 2020).

3 https://ec.europa.eu/eurostat/databrowser/view/sdg_04_60/default/line?lang=en 
Table 1 Employment and social targets in the Europe 2020 Strategy and in the EPSR Action Plan

\begin{tabular}{|c|c|c|c|c|}
\hline \multirow[b]{2}{*}{ Indicators } & \multicolumn{2}{|c|}{ Europe 2020 Strategy (2010-2020) } & \multicolumn{2}{|c|}{ Action Plan EPSR (2021-2030) } \\
\hline & Situation in 2010 & Target & $\begin{array}{r}\text { Situation in } \\
2019 / 2020\end{array}$ & Target \\
\hline $\begin{array}{l}\text { Employment } \\
\text { rate }\end{array}$ & $69 \%$ & $75 \%$ & $73 \%$ (in 2020) & $78 \%$ \\
\hline Poverty level & 73 million & $\begin{array}{l}53 \text { million } \\
\text { (reduction } \\
\text { of at least } \\
20 \text { million) }\end{array}$ & $\begin{array}{r}69 \text { million } \\
\text { (in 2019) } \\
\text { (reduction } \\
\text { of } 4 \text { million) }\end{array}$ & $\begin{array}{r}54 \text { million } \\
\text { (reduction } \\
\text { of at least } 15 \\
\text { million) }\end{array}$ \\
\hline
\end{tabular}

Source: Authors' own elaboration based on Eurostat data (as available on 20 May 2021).

\section{The EPSR: a modest impact so far}

From the moment of its proclamation in Gothenburg in 2017, it was clear that the implementation of the ESPR principles was to be primarily entrusted to the Member States (Rasnača 2017). The legislative contribution of the EU has therefore so far been limited. It consists of the 2019 Directives on transparent and predictable working conditions and on work-life balance for parents and carers, whose material and personal scope of application is rather narrow, and the Council Recommendation on access to social protection, which lacks binding force.

At the EU level, the EPSR was expected to be implemented mainly in the framework of the European Semester, with the support of a dedicated instrument, the Social Scoreboard, which is a statistics-based document created to monitor progress on some of the EPSR's principles. The European Semester unfolds in annual cycles, and the EPSR and the Social Scoreboard are intended to influence the different programmatic documents that characterise the various stages of the process. The cycle opens in autumn with the Annual Growth Survey (AGS), ${ }^{4}$ which is the document in which the Commission defines the policy priorities and the strategy to achieve them. At the same time, the Commission drafts the Joint Employment Report (JEP), which provides an overview of labour and social developments in the Member States. Then, in February, the Commission publishes the Country Reports, in which it gives an assessment of the national economic, employment and social situations. In April, Member States produce their National Reform Programmes outlining policy initiatives to address the shortcomings identified in the context of the present and previous Semester cycles. Finally, in the summer, the European Council, based on a proposal from the Commission, adopts Country-Specific Recommendations (CSRs) containing indications on how to improve the National Reform Programmes.

As illustrated in Figure 1, an analysis of the Semester cycles since 2018, which marks the first year of the EPSR and Social Scoreboard's introduction, indicates that their impact has actually so far been quite negligible. The adoption of the EPSR does not in itself seem to have marked a shift in redirecting the AGS

4 This became the 'Annual Sustainable Growth Strategy' (ASGS) in 2020 and in 2021. 
towards a more social perspective, which arguably only occurred in 2020 when a 'fairness and inclusivity' dimension began to emerge (European Commission 2020). Although the JEP and the Country Reports have both included a section dedicated to an analysis of the Social Scoreboard, this has not been reflected in the National Reform Programmes, which give little or no consideration to the EPSR or the Social Scoreboard. Nor did the CSRs, which arguably represent the most normative element of the governance cycle, show particular 'social sensitivity' in 2018 and 2019. Rather, in a clear indication of continuity from the previous CSRs, the majority of the recommendations were focused on competitiveness, economic growth and macroeconomic stability (Clauwaert 2019).

Figure 1 The modest impact of the EPSR and Social Scoreboard in the 2018/2019/2020 European Semester cycles

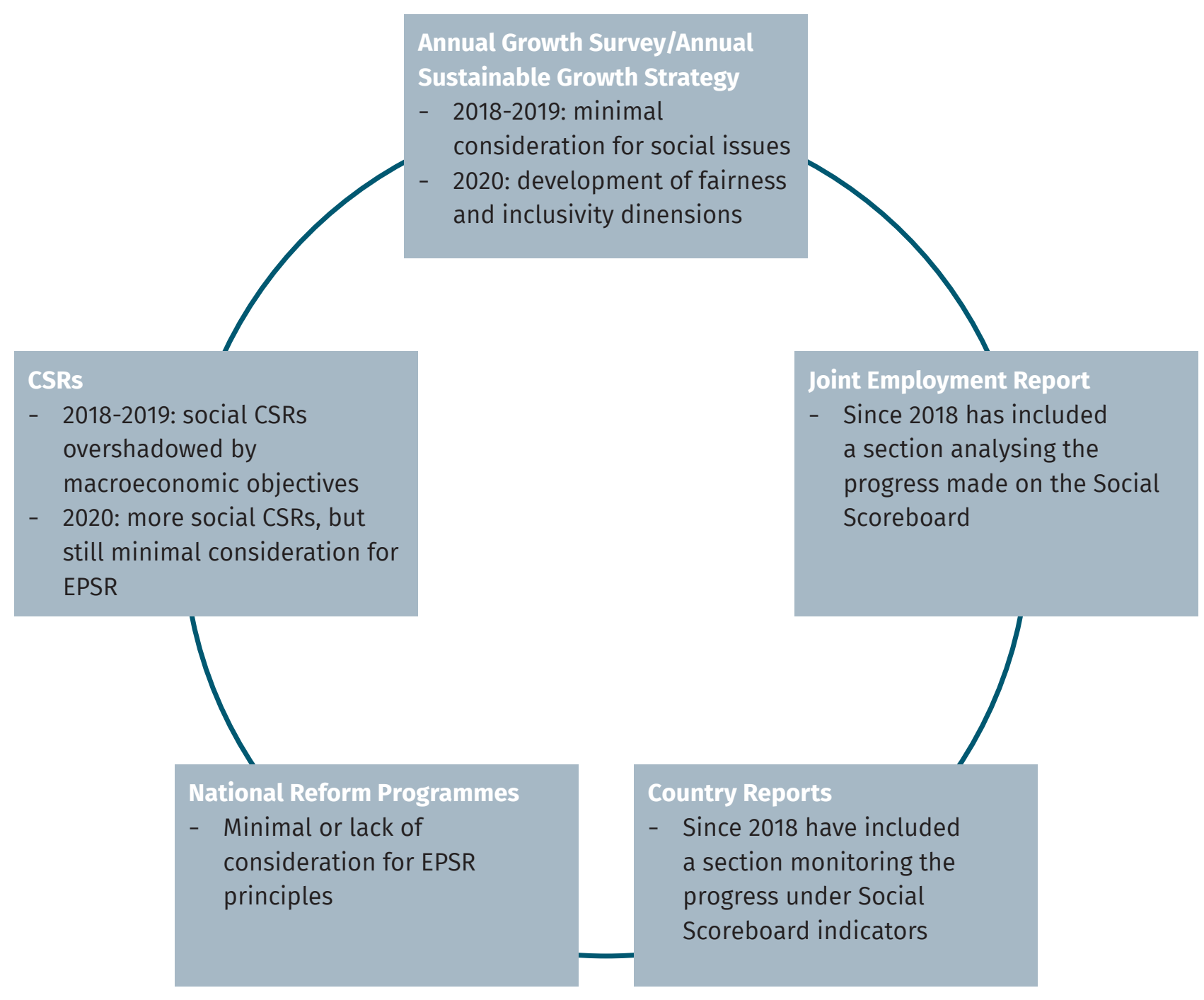

Source: Authors' own elaboration. 
A more social reorientation within the CSRs emerged only in 2020, when most national governments were instructed to put in place or improve their systems of income support and social protection and ensure greater inclusion of the most vulnerable groups within the population (Rainone 2020). The more socialoriented outlook of the 2020 CSRs, however, is directly linked to the exceptional easing of fiscal policy surveillance - resulting from the temporary suspension of the budgetary rules of the Stability and Growth Pact due to the Covid-19 pandemic - rather than to the EPSR.

The limited resonance and practical significance of the EPSR, both in terms of legislation and its place within the European Semester, clearly demonstrates the urgent need to boost its implementation and effectiveness.

\section{The Action Plan: still waiting for a game changer}

The Action Plan represents the Commission's commitment to implementing the EPSR and to making it the 'beacon guiding [EU institutions and national governments] towards a strong Social Europe and [setting] the vision for our new "social rulebook"' (Commission 2021b). The Action Plan is informed by the 20 principles of the EPSR and it reads as a rather pragmatic to-do list, primarily addressing the need for a sustainable and inclusive growth model and a fair digital and ecological transition. The outlined initiatives range from labour market inclusivity and upskilling to health and long-term care, measures to combat homelessness, working conditions and education, and other social protection and social assistance aspects. The Action Plan integrates the EPSR into the EU recovery strategy and abandons the rhetoric of austerity characteristic of the EU programmatic and policy documents that were published following the European sovereign debt crisis. Moreover, with the aim of modernising labour market policies and facilitating job transitions into growing sectors such as green and digital, the Commission presented a new instrument: Effective Active Support to Employment (EASE).

When it comes to assessing the potential reverberations of the Action Plan for EU and national policies, however, these promising elements must be balanced against their limitations. The outlined policy solutions primarily address those principles of the EPSR concerning labour market aspects, and less so those dedicated to the overall betterment of working and living conditions. Beside the already proposed Directives on pay transparency and adequate minimum wages, the Action Plan addresses labour standards in a limited number of legislative initiatives, notably on collective bargaining for autonomous workers who are in a vulnerable position and on the working conditions of platform workers. The Commission also announced a regulation on artificial intelligence (AI), but the current proposal does not adequately engage with the labour-related implications and risks of enhanced surveillance and algorithmic management tools at the workplace (Ponce Del Castillo 2020).

The focus of the Action Plan is mainly on empowering the workforce with the adequate resources to weather the labour market adjustments (or even displacements) that the digital and green transitions will inevitably produce. 
For instance, the Commission calls on the Member States to dedicate at least 22 billion euros to youth employment support, notably to create skills-enhancing traineeships. The same applies for EASE, which has been created to counterbalance the withdrawal of furlough schemes and to promote a job-rich recovery and skills development. Moreover, it does not provide additional resources to national governments, instead redirecting the funding that Member States will receive through the NextGenerationEU packages. While emphasising skills reinforcement is undoubtedly necessary to reach the $60 \%$ training target, little has been said on how to ensure that the economic and social agenda does not cause a deterioration of working conditions and an increase in precariousness (Franklin 2021). Furthermore, the Action Plan does not outline specific promotional measure, not even in the 'soft law' arsenal, to implement Principles 7 and 8 of the EPSR, respectively on social dialogue and on the right to information, consultation and participation. Overall, in fact, the Action Plan does not contain any ground-breaking implementation initiatives.

A similar assessment can be made of the role that the Action Plan confers to the EPSR in the context of the European Semester, despite the introduction of some substantial changes with respect to the former governance cycles. A first novelty is the revision of the Social Scoreboard, which now has a broader coverage. New indicators on adult learning participation, the child poverty rate, the disability employment gap, and the housing cost overburden rate ${ }^{5}$ have been added. Some of the existing indicators have been updated to better benchmark developments in social inclusion and social protection, including indicators on healthcare and long-term care, risk of poverty, and coverage of unemployment benefits. Moreover, as mentioned above, the Action Plan has intertwined the implementation of the EPSR with the EU recovery strategy and, more precisely, with the funds that the Member States will receive under the new financial instrument, NextGenerationEU. Solely for the 2021 Semester cycle, the Country Reports and the National Reform Programmes have been replaced by the National Recovery and Resilience Plans, in which Member States outline strategic reforms and investments they are planning to make and are encouraged to make best use of the funds to accelerate the implementation of the EPSR (European Commission 2021b).

These changes, while in theory highlighting the importance of the EPSR and of the Social Scoreboard in the EU's recovery, cannot correct the absence of legal binding force. It is disappointing that the implementation of the EPSR is not supported, for instance, by the establishment of minimum required investments in the social field or by the inclusion of social conditionality clauses, ensuring that the National Recovery and Resilience Plans will not lead to the weakening of social standards.

This contrasts sharply with the Commission's approach towards other priorities, evidently seen as more urgent for the EU agenda. For instance, in their Recovery and Resilience Plans Member States are required to allocate a minimum of $37 \%$ and $20 \%$ of their expenditure to the climate and digital

5 Defined by Eurostat as the percentage of the population living in households where their total housing costs represent more than $40 \%$ of their disposable income. 
transitions, respectively (European Commission 2020). Moreover, the 2021 European Semester cycle has established a 'green conditionality' clause, also referred to as the 'do no significant harm' principle, whereby no measure on the implementation of reforms and investments included in the plan shall cause significant harm to the environmental objectives of the EU (European Commission 2021a). But it is clear that the same political willingness simply does not materialise in relation to social objectives. It suffices to note that in the seven flagship areas in the 2021 Annual Sustainable Growth Strategy in which Member States are asked to redirect their investments within the Semester cycle, only one, 'Reskill and Upskill', relates to the labour sphere (European Commission 2020).

Overall, the new elements introduced in the Action Plan do not effectively address the shortcomings that have been previously identified in relation to the implementation of the EPSR principles (Potocka-Sionek and Aloisi 2021). Therefore, there are no indications that the role of the EPSR in EU policymaking will be substantially enhanced and will provide effective support in achieving the EU's social and employment targets.

\section{Concluding remarks and policy recommendations}

This policy brief has shown that, while much needed, the Action Plan does not endow the EPSR with sufficiently innovative implementation tools. In order to seize the momentum created by the Porto Social Summit and to boost the potential of the Action Plan with regard to its social and employment objectives, it will be crucial to give the EPSR greater capacity to effectively influence EU and Member States' policies.

It will be necessary to enrich the legislative agenda and push it towards measures to combat precariousness and strengthen social security and social assistance systems. The EU could also make more extensive use of the legislative competences conferred by the Treaties, which offer the potential to adopt measures on a vast range of subjects in the labour and social fields, from improvement of working conditions to social security and social protection, health and safety, information and consultation of workers, and labour market integration.

In terms of governance, there is an urgent need to reinforce the role of the EPSR and the Social Scoreboard within the European Semester. This could be done by enhancing their legal status or by establishing binding social safeguards promoting working and living conditions (or at least guaranteeing that they do not deteriorate), along the lines of what has been introduced to support the digital and ecological transitions and has been in place for over a decade in relation to macroeconomic objectives (Degryse et al. 2013).

The Commission will review the Action Plan in 2025. This may also be a good moment to reconsider the desirability of a full employment objective if efforts to achieve it contribute little to the quality of living and working conditions and to the pursuit of social priorities within the EU integration process. 


\section{References}

Clauwaert S. (2019) The country-specific recommendations (CSRs) in the social field: an overview and comparison. Update including the CSRs 2019-2020, Background analysis 2019.03, Brussels, ETUI.

Degryse C., Jepsen M. and Pochet P. (2013) The Euro crisis and its impact on national and European social policies, Working Paper 2013.05, Brussels, ETUI.

European Commission (2020) Communication from the Commission to the European Parliament, the European Council, the Council, the European Central Bank, the European Economic and Social Committee, the Committee of the Regions and the European Investment Bank - Annual sustainable growth strategy 2021, COM (2020)575 final, 17 September 2020.

European Commission (2021a) Commission staff working document, Guidance to Member States, recovery and resilience plans, SWD (2021)12 final, 22 January 2021.

European Commission (2021b) Communication from the Commission to the European Parliament, the Council, the European Economic and Social Committee and the Committee of the Regions, The European Pillar of Social Rights Action Plan, COM (2021) 102 final, 4 March 2021.

European Commission (2021c) Commission staff working document accompanying the Communication from the Commission to the European Parliament, the Council, the European Economic and Social Committee and the Committee of the Regions. The European Pillar of Social Rights Action Plan, SWD (2021) 46 final, 4 March 2021.

Franklin P. (2021) Quality jobs as well as jabs: protecting health by tackling precarious work, Policy brief 2021.04, Brussels, ETUI.

Fernandes S. and Kerneïs K. (2021) The Porto Social Summit: turning principles into actions, Jacques Delors Institute Blog, 3 May 2021. https:// bit.ly/3bhTfFi

Potocka-Sionek N. and Aloisi A. (2021) ‘Festina lente': the ILO and EU agendas on the digital transformation of work, International Journal of Comparative Labour Law and Industrial Relations, 37 (1), 35-64.

Ponce Del Castillo A. (2020) Labour in the age of Al: why regulation is needed to protect workers, Foresight Brief \#8, Brussels, ETUI.

Rasnača Z. (2017) Bridging the gaps or falling short? The European Pillar of Social Rights and what it can bring to EU-level policymaking, Working Paper 2017.05, Brussels, ETUI.

Rainone S. (2020) An overview of the 2020-2021 country-specific recommendations (CSRs) in the social field, Background analysis 2020.01, Brussels, ETUI.

All links were checked on 16 June 2021.

ETUI publications are published to elicit comment and to encourage debate. The views expressed are those of the author(s) alone and do not necessarily represent the views of the ETUI nor those of the members of its general assembly.

The ETUI Policy Brief series is edited jointly by Nicola Countouris, Jan Drahokoupil, Philippe Pochet, Aída Ponce Del Castillo, Kurt Vandaele and Sigurt Vitols.

The editor responsible for this issue is Philippe Pochet, ppochet@etui.org

This electronic publication, as well as previous issues of the ETUI Policy Briefs, is available at www.etui.org/publications. You may find further information on the ETUI at www.etui.org.

(c) ETUI aisbl, Brussels, June 2021.

All rights reserved. ISSN 2031-8782

The ETUI is financially supported by the European Union. The European Union is not responsible for any use made of the information contained in this publication. 